Henning, Günter:

[Rezension von: Gedeon, Andras, Science and technology in medicine, an illustrated account based on ninety-nine landmark publications for five centuries]

Zuerst erschienen in: Biomedizinische Technik = Biomedical Engineering. - Berlin [u.a.] : de Gruyter. - 53 (2008), 2, p. 91-92.

Erstveröffentlichung: $\quad$ 2008-03-27

ISSN (online): $\quad$ 1862-278X

ISSN (print): $\quad$ 0013-5585

DOI: $\quad$ 10.1515/BMT.2008.012

[Zuletzt gesehen: 43696]

„Im Rahmen der hochschulweiten Open-Access-Strategie für die Zweitveröffentlichung identifiziert durch die Universitätsbibliothek IImenau. “

"Within the academic Open Access Strategy identified for deposition by IImenau University Library."

„Dieser Beitrag ist mit Zustimmung des Rechteinhabers aufgrund einer (DFGgeförderten) Allianz- bzw. Nationallizenz frei zugänglich."

"This publication is with permission of the rights owner freely accessible due to an Alliance licence and a national licence (funded by the DFG, German

Research Foundation) respectively." 


\section{Science and technology in medicine: an illustrated account based on ninety-nine landmark publications from five centuries}

\author{
By Andras Gedeon \\ Springer Science and Business Media Inc., \\ New York, 2006 \\ Hardcover, VII, 551 pp., 1130 illustrations in color \\ Price: $€ 74.95 /$ US $\$ 89.95$ \\ ISBN 9780387278742
}

To analyze the influence of science and technology on the development of medicine over a time span of the last five centuries seems to be a huge task; the results of it could well fill an encyclopedic multi-volume monograph. Gedeon meets this challenge, but his approach is exceptional: this multidisciplinary impact on medicine is characterized by a selection of ninety-nine outstanding "landmark" contributions. Thereby, the number ninetynine is chosen as a symbol to remind the reader that this subjective selection could easily be changed to her/his priorities.

According to this basic concept, the book is organized in ninety-nine chapters, each of which is devoted to a landmark publication. Each chapter starts with a brief CV of the scientist followed by a concise description of the invention. Another paragraph opens up a historical perspective from preceding works, providing prerequisites for the invention up to subsequent (constitutive) or current contributions. Most of the space is reserved for excellent reproductions of core elements of the original papers with fascinating illustrations, drawings and photos.

To select the ninety-nine milestone achievements out of almost innumerable multidisciplinary contributions to the development of medical science and practice over five centuries is without a doubt a difficult task. Gedeon starts his selection with Albrecht Dürer's attempt to apply mathematics for describing the proportions of the human body (1528). This fundamental work stimulated and enabled a lot of subsequent research, e.g., related to body mechanics and body movement dynamics. In the following chapters, the reader will find many well-known contributions and their authors, such as Santorio (introducing the mechanistic view of the body), Hooke (with his early animal experiments for artificial ventilation, 1667), Robert Boyle (experiments on the physical and chemical properties of blood, 1683) or Stephen Hales (invasive blood pressure measurements, 1727). But there are also names to be found which - at least at the first glance - one would not associate with medicine: Johannes Kepler, e.g., is well renowned for his groundbreaking research in astronomy, but he also published findings in retinal image generation (1604). The physicist Daniel Bernoulli (founder of the science of hydrodynamics) presented a kinetic theory of gases, but he also suggests that his results can be applied to "the flow of blood in veins and arteries" (1738).

Although the book allows a broad view of the influence of a multitude of scientific disciplines (biology, chemistry, mathematics, physics, etc.) to the progress of medicine, the main focus is clearly on the impact of technology. The interested reader will find a lot of material from early inventions (e.g., Ambroise Pare's new surgical techniques and prostheses, 1575) up to outstanding contemporary research results (e.g., Paul Lauterbur's contribution to NMR imaging technology, 1971 or Michael Phelps work on positron emission tomography, 1975). Some of the examples included open up surprising insights, e.g., about Jallabert's early research on electrical stimulation of muscles and paralysis treatment, 1748 or Abel's first successful demonstration of dialysis in dogs, 1914. With this comprehensive technology-related material, the book also provides a distinguished contribution for working up the history of Biomedical Engineering as a scientific discipline.

Looking at the sample of the 99 landmark publications, the reader will certainly agree that most of them are outstanding contributions to the development of medicine. But, such a sample would always be a very personal selection and therefore - speaking with Gedeon - "...is justly subject to criticism". From the position of the reviewer, some of the landmarks are undoubtedly milestones in the development of science, technology or even society, but with no specific or prior reference to medicine, e.g., Maxwell's work on control theory (1868), Thomson's discovery of the electron (1897), the invention of the first programmable electronic computer ENIAC (Eckert/Mauchly, 1945) or the development of a packet protocol for digital data communication (Cerf/Kahn, 1974).

The book ends with a comprehensive bibliography, a timeline presentation and a graphical representation of interconnections between the landmark contributions.

For a biomedical engineer, this is a fascinating book delivering a lot of new information and a deeper insight into the history of this multidisciplinary scientific field. The tight texts are focused on the matter and the volume is richly illustrated with high-quality facsimile reproductions from the original publications. So, to read the book is not at all tiring but rather entertaining, and once started it is really difficult to lay it aside. Therefore, this remarkable 
monograph should not be confined to the stock of scientific libraries, but it should have a prominent place on the bookshelf of every biomedical engineer, medical physicist and of all scientists who in some way are connected with medical science or practice.

\section{Günter Henning}

Technical University IImenau, Computer Science and Automation Department, Institute for Biomedical Engineering and Informatics, 98684 IImenau, Germany, e-mail: guenter.henning@tu-ilmenau.de 